\title{
1 Historicising Literary Culture: Communication, Contingency, Contexture
}

\section{Communication}

In order to understand early modern literary culture, we need to reconstruct the conditions of literary communication prior to the modern concept of literature as aesthetic (fictional) discourse. How did literature work? What were the functions of reading and writing in seventeenth-century England? My suggestion is to describe literary forms in relation to, and at times in conflict with, socio-cultural formations or arrangements in which these forms are negotiated, modified, and continued. The aesthetic, then, is not an independent realm that can be taken for granted or posited as given. If we want to come closer to an idea of what literary communication might mean, we will have to question and explore more closely the (historically specific) modes of access to (literary) texts.

For a long time, this question of access was deemed unproblematic: either literature was mere appearance and had no genuine knowledge to offer, or it dealt in pseudo-statements with no truth value. As Sir Philip Sidney famously wrote in his Defence of Poesie in c. 1579: "Now, for the poet, he nothing affirms, and therefore never lieth" (Sidney 1973, 102). Literature as fictional discourse cannot lie, cannot not tell the truth, because telling the truth is not the point of fiction. Because literature makes no truth claims, it cannot be judged according to the "fact convention" (Schmidt 1982, 87) that dominates real-life communication. Literary language, in this view, would be a special kind of language, a purely fictional mode of utterance.

In order to go beyond these conventional models, it is necessary to conceptualise and historicise the modes of access to literary texts. It may be useful to begin doing so in terms of a theory that does not conceive of media as message-bearers or carriers of information but as complex sensory arrangements that can trigger a range of experiences. These experiential effects are very difficult to rationalise or to describe either in a clear-cut definition of media or in traditional theories of aesthetics. They are more readily analysed in a communications-oriented approach. In Niklas Luhmann's systems theory, communication is a process that consists of three elements: 'information', 'utterance', and 'understanding'. Each of these operational units - (1) the possible intention of an origin, however inferred; (2) the verbal, material utterance, and (3) what a recipient takes the utterance to mean - can then be thematised, marked or underscored in follow-up communications. Communication, according to this theory, always happens, and its initial intent (the 'information') can never determine or control its possible outcome (understanding, misunderstanding, response) (Wilden 1987). Other perspectives on the theory and history of discourse, though not sharing these theoretical 
foundations, do share the assumption that the world they look at is "a world in which [...] the utterance cannot wholly determine the response" (Pocock 1985, 34). In media-theoretical terms, one would have to say that the effects of media on their recipients or participants, as the case may be, are incalculable. They can range from absolute fascination, heightened awareness or experiences of "flow" (Csikszentmihalyi 1990) to lack of interest or absolute boredom. If recipients attribute their emotional responses or aesthetic judgements to intrinsic qualities of what they have seen or heard, they may be subject to a familiar delusion. ${ }^{5}$

But even though there is a certain fixity about the written page so that, provided one knows the meaning of the signs, one should be able to know what a text is - "these words in this order" (Grabes 2013, 44, quoting Cameron 1962, 145) -, languages and contexts of utterance are unstable and subject to change, so that an utterance - even if it consists of the same words - need not, in fact will not stay the same when it is repeated. Texts, understood as utterances, do not remain the same over time but have a performative character. Two initial conclusions to be drawn from this, now commonplace in literary theory, are: firstly, that verbal constructs, such as literary texts, have no intrinsic univocal meaning, but, because of their linguistic nature, are ambiguous or multivalent: the sense of the words in the text has to be constructed by reference to a particular "universe of discourse" (Ogden and Richards 1927, 102) and their relation to the whole of a given text. In reading, then, we should pay attention to the "intratextual interaction of words" (Grabes 2013, 41). The second conclusion, following from this, is that any reading is not merely the reconstruction of a given verbal arrangement but a performative act, "intended to give rise to something else” (Jardine and Grafton 1990, 30). Reading, too, has a history (see, among many others, Darnton 1991, Chartier 1994).

It is the specific and different uses to which texts have (or might have) historically been put that constitutes the focal point of such criticism. For example, the habit of reading Virgil's Aeneid as a work of fiction is only one option among many; in former times, it was widely put to a rather more practical use as a medium of prophecy (the sortes Virgilianae). The communicative function of a text thus depends on a set of decisions made before, during, or after the actual experience of reading, and these decisions themselves depend on an array of factors (political, social, personal) that determine the reader's criteria.

Because all texts are essentially geared towards some kind of reader (even in cases when this reader is merely the author him- or herself), no 'actualisation' of a text's potential meaning, no interpretative act can be conceptualised without at least a hazy understanding of the reader's role. This role is embedded in historical and

5 Cf. Wimsatt and Beardsley 1954 for the New-Critical strategy of removing any personal or emotional responses from critical discourse for the sake of objective, formally 'correct' readings of literary texts. 
social contexts, depending on a wide range of variables from psychology to media history. In their effects on different audiences, geographically or historically, media, including texts - including those texts we have become used to calling 'literary' - are extremely diverse. It could be said that each act of reading is a unique and unrepeatable historical event. A famous short story by Borges illustrates this: a modern author who rewrites Cervantes's Don Quijote, though using exactly the same words, produces a completely different novel because he is writing it at a different time (Borges 1962). The meanings and functions of texts are subject to change in different historical or cultural contexts and in varying media arrangements. ${ }^{6}$

Yet a text usually is a determinant of those acts that ascribe meaning to it, so that there is a danger not only of under-but also of overestimating the importance of readers for the generation of meaning. The relation of texts, their language(s), and their contexts is subject to change; this includes earlier responses to a text, which may trigger re-evaluations of individual or communal readings that modify the perception of a text. Certainly, the concept of text would be meaningless without a concept of reading; but it would be an oversimplification to claim that a text consists merely and exclusively of its readings (cf. Fish 1980). After all, reading is not situated outside the historical process but is embedded in and modified by it. The cultural practice of reading is itself subject to change, and so are the ways in which access to literary communication has been and is being codified. A reading is never merely the reconstruction of something given in the text, but an interaction between texts and readers, a process of communication that cannot be controlled completely by any of its constituents: not by the author, nor by the reader alone, nor by the text. To quote J. G. A. Pocock $(1985,17)$, "when action and response are performed through the medium of language, we cannot absolutely distinguish the author's performance from the reader's response." What one can try to do, however, is reconstruct the unique set of conditions and assumptions involved in the actual performances of writing and reading, or of media experience, in a particular time and place. ${ }^{7}$

\section{Contingency}

In order to gain a better sense of literary culture in relation to media and social knowledge formations, I suggest the concepts of communication and contingency as fundamental to understanding how seventeenth-century literature 'works' and to account for the way it develops and changes. What do I mean by 'contingency' as a framing concept? In the past decades, the concept of contingency has become an increasingly

6 For a radical illustration of this, see Bohannan 1966; cf. Schwab 1996, 1-9.

7 I am thinking along the lines of reconstructive efforts like those of Wallace 1974-75; see also Jardine and Grafton 1990. 
central term in the humanities. From its classical roots in modal logic ${ }^{8}$ to its redefinitions in action theory, phenomenology, and systems theory, ${ }^{9}$ the concept of contingency has now advanced to the status of a key descriptive and explanatory category, if not the "defining attribute" (Luhmann 1998), for understanding modernity. Modernity, in this perspective, is characterised by an increased social awareness of contingency, by a knowledge that implies the knowledge of alternative possibilities to a given reality: the fact that 'things might as well be different'. This awareness has a dual nature in that it can focus, on the one hand, on the observation that things as they are might just as well be otherwise (contingency as possibility), and on the other hand on the observation that whatever occurs, even if it appears random and is caused by what Shakespeare calls "the shot of accident" and the "dart of chance" (in Othello 4.1), is nonetheless real and needs to be dealt with as such (contingency as destiny). The concept of contingency, in Luhmann's now classic formulation $(1984,152)$,

signifies something given (experienced, expected, thought, imagined) with regard to the observation that it may possibly be different; it signifies objects in the horizon of possible alterations. Because it presupposes the given world, it does not signify the possible in general but that which, seen from the point of view of reality, may possibly be different.

This definition can be related to descriptions of modern concepts of reality as variable and plural (Blumenberg 1979). "A new form of order that we can call modern," writes Bernhard Waldenfels $(1990,18)$, "makes headway when the suspicion is aroused that the order that seemed so steadfast and all-encompassing might only be one among other possible orders." It can also be connected, in more socio-political terms, to what has been described as the specific "constructive strategic disposition" of a modern social order, a rational form of social management that "limits contingency through the goal-oriented use of contingencies”, responding to its aspects of indeterminacy by putting its aspects of possibility to good use (Makropoulos 1998, 71; cf. Makropoulos 1997). Modern civilisation can thus be described as a culture of contingency, characterised by the productive duality of indeterminacy and possibility even to the point at which it forms the very basis on which society and social structure are seen to evolve, the point where traditional descriptions of society in terms of custom and grace give way to the political language of fortune (see Pocock 1975).

Beside its philosophical, sociological, and historical significance, the concept of contingency has communicative and epistemological implications. The indeterminacy or unpredictability of the future belongs first and foremost to the dimension of knowledge. In a sociological view, indeterminacy as the "cognitive correlate of contingency"

8 For the classical definitions (contingens est quod nec est impossibile nec necessarium; quod potest non esse; quod potest aliud esse), see Graevenitz and Marquard 1998, xi; Scheibe 1985, 5-6.

9 Cf. Bubner 1984, 35-36; Blumenberg 1981, 23, 47-48; Luhmann 1984, 148-90. In the development of Luhmann's theory, contingency advances from an action-theoretical to a radically constructivist concept. 
(Hahn 1998, 518, my translation) structures social interaction and produces necessities, inevitabilities, by establishing links between contingencies in communication and thus compensating for the lack of mutual understanding between communicants. This knowledge of contingency - or, more precisely, "this teleologically determined non-knowledge” (Simmel 1968, 259, my translation) - is a motivating force in modernity not only in the formation and evolution of societies, but also in the area of culture, not least in the formation and evolution of literary writing. Early modern forms of narrative, for example, become affected by the possibility that any one story might be told in many different ways, and - perhaps even worse - might be understood, or misunderstood, in as many or even more different ways. Again, there is a dual aspect of contingency that, on the one hand, opens up possibilities for telling many stories in many different ways but, on the other hand, also imposes limiting constraints on the forms in which stories can be told. In the process, narrative is increasingly forced to develop, justify, and defend its own discursive foundations (see Greiner and Moog-Grünewald 2000; Lobsien 2000). This becomes particularly evident in the literary culture of the seventeenth century.

In early modernity, the role of the audience and their understanding is increasingly regarded as the most difficult and unpredictable instance in the communication process; hence all those "peritexts" (Genette 1997) - dedications, prefaces, title pages, frontispieces, errata lists, prologues, and epilogues - that surround the main text and often provide some form of guidance for the reader in an attempt to reduce the number of possible interpretations. There is a growing awareness in this process of the irreducible individuality (or incalculability) of readers and of the concomitant contingency of reading (Kroll 1991, 72-73, 77, 85).

This new predicament of writers in the early modern public sphere calls for new strategies in literary communication. Prefaces, epilogues, frontispieces, and other peripheral texts become strategic sites of debate, if not of intellectual warfare. They are the battlegrounds on which writers engage their colleagues and readers over the functional specifics of texts and their role as media of communication (as well as instruments of propaganda). The preface in particular becomes "so popular with the reading public that, it was said, books sold less well without them" (Sharpe 2000a, 56; cf. Dunn 1994). New forms of textual presentation, distribution, and marketing emerge. The outcome of this dynamic is the stabilisation, in the late seventeenth and early eighteenth century, of an "isomorphism of knowledge, literary structure, and implied procedures of interpretation” (Patey 1984, 175; cf. Shapiro 1983, van Leeuwen 1963, Hacking 1975). This isomorphism, or parallelism - which is also, I shall argue, the result of a successful socio-cultural compromise expressed in aesthetic terms as 'neoclassicism' - hinges on the concept of probability and its attendant tropes: inference, conjecture, circumstances, casuistry, sagacity, verisimilitude, so that "all knowing, all learning” becomes "a process of inference from signs", a process that creates structures which "require the exercise of that very judgment which the author wishes to teach" (Patey 1984, 179). Such a world of probable signs, which is explored in the 
emerging literary form of the novel, is none other than a world of contingency. The earliest novels deal with the lack of access to the inner lives of others, the insight that "all we know of others we know by signs: all our knowledge is irremediably mediate" (188).

To sum up: for literary communication (on its several levels of production, performance, and reception) in modernity, contingency is at once an enabling and a constraining factor - enabling inasmuch as it offers new possibilities of literary form, constraining inasmuch as these new forms are not free-floating and self-enclosed entities but are situated in a setting of contextual determinants, comprising forms that already exist as well as other areas of social communication. As a decisive attribute of modernity, contingency can thus become part of a "self-conscious procedure" (Patey 1984, 179) of literary writing and reading, the epistemological foundation of what I term, with Michel de Certeau (1986, 91), a “politics of utterance.”

\section{Contexture}

As Michael McKeon has observed, "the very access to an abstract category 'literature' is to some degree anachronistic at this time, referring either backward to a broadly inclusive idea of litterae humaniores or forward to our modern notion of a sharply defined and autonomous realm of written objects that possess an 'aesthetic' character and value” (1987b, 36; cf. Reiss 1992). In other words, “literature' did not become associated with specifically imaginative writing, as opposed to historical or scientific writing, until much later" (MacLean 1995, 7-8). This does not preclude the observation of the growing cultural and social importance of literature in this sense in the period: "by 1660, literature had established its own irreversible authority as a socially constitutive field of public activity" (13). Distinctions between textual 'kinds' were handled in a complex and flexible manner rather than as explicit demarcations among different genres. Logic, rhetoric, and poetic discourse were related and not strictly isolated forms of communication. ${ }^{10}$ They are, to use a word that is part of the early modern vocabulary, bound up in a 'contexture', in a continuum of mutual influence that affects the form, content, and meaning of individual texts. In contrast to a text-context duality, 'contexture' emphasises the connections and the competition between different texts, largely regardless of genre. The word "contexture" can refer to the completion of a work, the act of tying together its

10 Cf. Howell 1956, 4: "Englishmen of these two centuries [1500-1700] did not waste their time in the vain effort to deny to poetry a primarily communicative function. Nor had the science of aesthetics yet been invented to insulate poetry from any contact with logic and rhetoric. Instead, poetry was considered to be the third great form of communication, open and popular but not fully explained by rhetoric, concise and lean but not fully explained by logic." 
"parcells" (Davenant 1971, 24), con-texturing it for its first readers and thus weaving it into the web of public discourse.

Whereas the term 'context' is often seen to imply a hierarchy of value and/or a determinism of agency between texts and their 'background', 'contexture' connotes a controlled levelling of such a hierarchy because it emphasises the discursive and public status of textuality in general and the competitiveness of texts, largely regardless of genre, in the early modern public sphere. This levelling is not to be confused with a poststructuralist notion of écriture or a simplistic reading of culture-as-text. It does not preclude the observance, and the observation, of genre distinctions in textual engagements and, in this respect, it is not a complete levelling of all discourse. Contextural rather than merely contextual reconstitution implies a continuum of semantic connections and effects, a mutual give and take between situations of writing, textual structures, and processes of response. For example, as I shall argue below in ch. 3 and 4, seventeenth-century literary theory, natural philosophy, and political thought are bound up in such a contexture of overlap and exchange between ideas, keywords, and tropes.

Contextures depend on the circulation of texts and ideas. Stephen Greenblatt's well-known metaphor of "the circulation of social energy" (1988), coined in the heyday of the New Historicism, is an apt description here also because the seventeenth century was itself obsessed with the language of circulation, a foundational vocabulary in descriptions of physiological, political, economic, and literary 'systems' from Edward Misselden's The Circle of Commerce (1623) and the "boundless Circles" of empire in Dryden's Astræa Redux (1956, 30, 1. 299) to William Harvey's works on the motion of the heart (De Motu Cordis, 1628) and the circulation of the blood (De Circulatione Sanguinis, 1649) (Rogers 1996, 16-27; Kroll 2000, 104-11; Kroll 2007).

In order to reconstruct early modern literary culture, one needs a concept of literary production as a form of social action and of literary reception as performative rather than merely reconstitutive (Todorov 1976-77; Jauss 1970-71). The word 'contexture' emphasises the active, performative component of linking and intertwining elements into a structure, composition or texture: it underlines the operational aspects of discourse as process. The texts themselves often display an awareness of their performative nature: we get a glimpse of this process of negotiation in Dryden's naval scene at the beginning of the Essay of Dramatick Poesie, a glimpse of the crucial question how to address an audience that is always prone to disintegration, and how

11 Cf. Culler 1988, xiv on context: "But the notion of context frequently oversimplifies rather than enriches discussion, since the opposition between an act and its context seems to presume that the context is given and determines the meaning of the act. We know, of course, that things are not so simple: context is not fundamentally different from what it contextualizes; context is not given but produced; what belongs to a context is determined by interpretive strategies; contexts are just as much in need of elucidation as events; and the meaning of a context is determined by events. Yet when we use the term context we slip back into the simple model it proposes." 
to use communication in such a way that it can transform this "dividuall" (Milton 1953b, 544) ${ }^{12}$ audience into a unity.

As historically contingent performances, acts of writing and reading circumscribe the 'event horizon' of texts and therefore allow us to describe the functional change of literary communication. The concept of functional change requires a concept of reading that is not located outside or beyond historical processes but one that is embedded in the media history of writing and reading as cultural practices. Through investigating functional change, we can hope to arrive at a "thick description" (Ryle 1971, Geertz 1973) or even a mapping of the points of intersection between literary and cultural forms of knowledge.

Variability, dissociation, even disorder, can be regarded as keywords in the description of early modern literary culture, which is a literary culture before 'literature', before the codification of literary communication into a functionally specific (and socially much less problematic) medium but one that is already "deeply imbued with literate habits of mind" (Fox 1996, 90), a culture deeply affected by the social impact of writing and its various cultural uses. A recognisably 'modern' configuration of literary culture emerges from the dissolution of the closed medieval world picture, accompanied by a vast array of new discoveries in natural science, economics, and geographical exploration, from Copernicus to Columbus, resulting in a new concept of reality as "open context” (Blumenberg 1979; see also Reiss 1982a, Mahler 2019). The circulation of texts is increasingly uncoupled from direct interpersonal contexts of interaction. They become part of a more general endeavour to increase knowledge about a world that is now realised as still largely undiscovered, and to deal with the problems that arise from this increase - leading, in many cases, to an aesthetics of "unevenness" and "uncertainty" (Augustine 2018, 2).

When an older cultural formation erodes and is slowly superseded by a new one, there is a time of overlap between residual, dominant, and emergent structures (Williams 1977), an overlap that will create frictions or crisies. It appears that only a form of communication that is not system-specific can address these overlaps without necessarily privileging one possible solution over others. This form of communication would have to be significantly different from others in its function. If science and other organisational institutions carve up reality in a certain way (determined by their need for specific solutions to specific problems) and thus reduce complexity,

12 In this context of his Areopagitica, Milton uses the word to denote the dissociation of external "piety" from genuine religious faith: "So that a man may say his religion is now no more within himself, but is becom a dividuall movable" (1953b, 544). Yet its semantic range can perhaps be extended to a more general socio-psychological description of dissociation in early modernity, a description that comprises both social processes and 'psychological' notions of substantial (individual) vs. accidental (dividual) elements of 'selfhood'. Cf. Paradise Lost 12.82-84, where Milton argues in political terms for a moral psychology in which "true liberty" and "right reason" should have "no dividual being" $(1998,651)$. 
this other form of communication will address these disciplinary or systemic exclusions, creating a virtual contact zone for the encounter and the testing of other possible solutions (Berensmeyer 2003).

Literary communication before 1700 is less concerned with legitimising its fictionality vis à vis other forms of communication than with thematising ongoing transformations. Early modern literary culture, under the influence of humanist skepticism, often displays a proto-constructivist awareness of the fact that different discourses, rhetorics, and media can shape perceptions of what reality is or appears to be in very different ways. In the light of this awareness, texts explicitly overstep their generic limits (conventions) and play with (anticipate and then counteract) their readers' expectations. Shakespeare's plays, for example, engage in a sophisticated, highly reflexive, and at the same time highly entertaining dissolution and recombination of different discourses (see e.g. Iser 1993).

The open context which, according to Blumenberg (1979), is the key concept of reality in the early modern period, has a material correlate not only in the expansion of the known world through the 'discovery' of America, but also in the introduction of print culture and the massive circulation of written and printed matter, because the increasing production of knowledge not only expands the communicative range of written words but also creates an enormous complexity and openness of situations of communication. It also contributes to diagnoses of increasing uncertainty and disintegration. This is a radical change because textual utterances are uncoupled from the physical presence of human bodies and from immediate personal interaction (Gumbrecht 1985). New strategies have to be invented to make the connection between texts and their possible readers less susceptible to irritations. Among these texts, it appears that a certain type develops a paradoxical convention of its own: the convention of being in a strict sense unconventional, by allowing a heterogeneous multiplicity of perspectives and thematising possible clashes between other conventions, other organisational forms of carving up reality. Such texts may have appeared before, but now they no longer occupy merely a marginal place as they did in the high middle ages, for instance with troubadour poetry. Now, there is an increasing number of "texts with a negating character", which question the established sense-making proposals of social norms or conventions and do so by presenting literary "counter-worlds" (Gumbrecht 1980, 127, my translation).

The printed book in particular is geared towards an audience that could and probably would be much more diffuse than that of a speaker who addressed a gathering of listeners in person. The former certainty, or at least high probability, of a shared horizon of meaning can thus no longer be guaranteed. According to many critics, this structural change intensifies the sense of a "polarization between the spaces of everyday meaning and fictional meaning" and "the experience of a clear-cut boundary 
between these two spheres" (Gumbrecht 1990, 177, 181, my translation). ${ }^{13}$ Early modern readers acknowledge the benefits as well as uncertainties inherent in print communication. The institutions of censorship in early modern Europe, however efficient or inefficient they may have been in practice (see Patterson 1984), provide evidence enough for the awareness of such uncertainty and for the social need to deal with it in some way. The effects of printed texts on their potential recipients were sometimes presented in terms of risks and even potentially lethal consequences; these dangers required a reader's active participation and watchfulness to the point of resistance. As the Canon of Toledo explains in his famous speech in book 1, chapter 47 of Don Quijote, "lying fictions must be wedded to the intelligence of those who read them" (Cervantes 1987, 1: 906-7; my translation). Adrian Johns has noted a similar "culture of discredit surrounding printed books" in seventeenth-century England, with the concomitant emphasis on the necessity of readers employing their critical faculties in order to produce "safe and true knowledge" (Johns 1998, 423). In early modernity, the 'fictionality' of a text thus depends to a great extent on its readers' acceptance. Not only Don Quijote took novels literally. For instance, at least one early reader of William Baldwin's Beware the Cat (1584) mistook it as a libellous slander against Gregory Streamer, the story's - fictional - protagonist and narrator. But if early modern fictionality is to such a high degree subject to the perspective of observers, then it cannot be maintained as the essential characteristic of a certain text type or genre; on the contrary, it appears to have been a highly unstable function attributed to texts by observers in certain circumstances and according to certain - and sometimes maybe less certain - rules.

Rather than being compartmentalised into separate categories, public discourse in the seventeenth century proceeds from, and is indeed constituted by, a mixture of media, genres, and languages, a fertile (and cross-fertilising) criss-crossing of different idioms and modes of signification. The central feature of textuality in the seventeenth century is its emerging public nature. Literature in the first age of print is argumentative, hortatory, cautionary or deliberative, but always involved and enveloped in the public arena of which it is a part and which it helps constitute. Early modern readers do not seek the meaning of a poem, for example, in relation to its author's individuality, unless typified as the 'I' of "the constant lover" or "the lover unhappy" in Tottel's Miscellany, but in the argument it presents (in and to the public) and in the quality of this presentation. ${ }^{14}$ Seventeenth-century literary culture is

13 On the media change from oral to written to printed texts, next to the classic studies by Eisenstein 1979, Ong 1982, Finnegan 1988, Elsky 1989, Giesecke 1991, see also Luhmann 1992, Wellbery 1992, Marotti 1995, Johns 1998, Bohn 1999, Cochran 2001, Ezell 2003, McKitterick 2003.

14 Cf. Winn 1987, 1: “[P]oetry in his [Dryden's] culture was a public act: the attention paid to a new poem was far more likely to focus on its success as an argument and its quality as an artifact rather than on its overt or covert revelation of its author's soul; the fascination with childhood we find in Wordsworth and his contemporaries reflects a radically changed view of creativity.” 
still a highly rhetorical culture in its orientation towards a classical image of the forum as a public sphere in which social and political life emerges and is negotiated by the participants of public discourse. Given the political ideals of civic humanism and its indebtedness to classical rhetoric, it is no surprise that the spoken and written word is favoured in education over more sensuous forms of communication like the visual arts or music (see Winn 1987, 42-46; Skinner 1996, 19-40). There is a real sense in the seventeenth century that aesthetic decisions (e.g. whether to write in blank verse or heroic couplets) or theoretical programmes of literary writing (e.g. the neoclassical observation of the unities in drama) carry a direct political significance as well as claims to socially normative validity. ${ }^{15}$ Another fundamental feature of this public discourse is its competitive rather than conciliatory or consolidating nature. There is a strong sense of the divisions that characterise the public realm and the 'republic of letters'. What did this republic of letters look like, and what was it based on?

\section{Literary Culture}

Most people in the seventeenth century were still unable to read or write. Probably about seventy percent of the male population were illiterate, and almost the entire female population. However, those who did learn to read and write had a decent chance of proceeding to higher education (one in fifteen), ${ }^{16}$ and those who entered Oxford or Cambridge could not only expect a very good education - largely in Latin, which was still treated as a living language - but also professional opportunities after completing their studies. Furthermore, education in England was not entirely a privilege of the upper classes but was regularly open to boys of the middling sort (yeomen, artisans, tradesmen) and, in some cases, to talented children among the poor who could work their way through college as servants. Like today, education could open opportunities for upward social mobility. Yet the career opportunities opening up for these well-educated people were not academic. There was no professionalisation of philosophy, let alone literature, as an academic discipline. Those who published philosophical works did not do so because they thought of them as products of academic research. Likewise, those who produced what we may be tempted to call 'imaginative literature' did not do so because they considered writing

15 Cf. Hardison 1989, 219-25 (on Davenant's choice of the decasyllabic quatrain as a 'rational' form) and 258-76 (on rhyme vs. blank verse in Dryden and Milton). On the correlation between classical literary learning and contemporary politics in seventeenth-century England, see also Patterson 1986.

16 Tuck 1993, 2, whose calculation is based on information in Wrigley and Schofield 1981 and Stone 1964. Literacy was considerably higher in London (sixty percent of adult males); see Achinstein 1994, 12. 
their profession or because they could hope to make a living from the sale of their literary property. Although there was no difficulty in getting published, because publishing houses were flourishing, books were still quite expensive, not least because of the high cost of paper. ${ }^{17}$ The first edition of Hobbes's Leviathan cost eight shillings, "more than most ordinary laborers earned in a week" (Malcolm 1996, 14). Furthermore, the modern system of royalties did not exist, and any profits from print publication would accrue to the printer rather than the author, who had sold his or her work for a flat fee. The patronage system, as part of an early modern gift economy (see Fumerton 1991, Scott 2006, Heal 2014), enabled writers to profit more indirectly from dedicating their work to a patron. For the rest of their time, they had to rely on income from other sources, often as secretaries to a public official (like Spenser) or tutors in a private household (like Hobbes), positions that offered financial security, access to a wellstocked library, writing materials, and (not least) political protection or preferment.

The seventeenth-century 'republic of letters' is a very colourful and highly volatile place, "inhabited equally by churchmen, physicians, noblemen, officers of state, schoolmasters, and even, in the case of [. . . S Sir Kenelm Digby, a one-time amateur pirate” (Malcolm 1996, 14). There is great diversity and an "enormous variety of intellectual positions" (Tuck 1993, 4). Early modern culture, then, in the words of Richard Tuck (1993, 4), "was one where the way of looking at the world which anyone adopted depended very much on what kind of activity they were committed to." In this period, the idea of an 'autonomy' of literary texts in relation to other specified genres, or the idea of a 'literary' reading of certain texts as opposed to 'non-literary' or 'non-fictional' readings of certain other texts would have made no sense. Rather, what mattered to readers was the pragmatic, action-oriented use value of texts, including poetic texts. In the seventeenth century there were no professional readers of literature, no literary critics or literary magazines. Literary culture was part of a more general cultural layering of relational determinants of communication and action; a part that could be specified by its particular effects or by its utility for other forms of behaviour and activity, but a part that could not be observed as an independent, autonomous entity. It was a spider's web among other spider's webs.

Then as now there were of course no guaranteed recipes for literary success. But the insecurity of print communication - still, after all, a fairly new medium - was an experience that triggered an increased reflection on the specific differences of literary communication compared to other, more immediate forms of social interaction. Committing his translation of the Greek historian Thucydides to print (a work that expressly addresses the connection between language and the public sphere), Thomas Hobbes notes in 1628 that "there is something, I know not what, in the

17 Paper had to be imported from Europe, mostly from France and Italy, since the English paper industry was slow in developing. Around 1600, a ream of paper (500 sheets) would have cost between two and seven shillings. See Coleman 1958, 1-18; Daybell 2012, 30-52. 
censure of a multitude, more terrible than any single judgment, how severe or exact soever" (Hobbes 1975, 6). For this je ne sais quoi of print culture, contemporaries even if they were as eloquent as Hobbes - lacked a definite term. Print culture in early modernity extended but also weakened literary authorship as well as political authority to the point of their depersonalisation (see Sharpe 2000a, 28-29; Hobbes 1996, 1.16). As the unease about communicating to, and being judged by, complete strangers across vast distances of space and perhaps even time increased, so did the development of authorial strategies in response to this predicament - strategies "to contain the hermeneutic liberties of readers" (Sharpe 2000a, 44). ${ }^{18}$ Writers could never be quite certain whether what they committed to print would be understood 'correctly', the way they wanted it to be understood. They could never be quite sure of reaching their target audience and establishing a bond of communication - in the sense of a communal understanding - with their readers. Readers, in turn, had to learn to decipher signs of manipulation and propaganda, to develop their own terms for interpretation, and to read texts 'against the grain', especially during the Civil War, when a flood of pamphlets - more than 22,000 according to some estimates (Achinstein 1994) - incited them to political action.

Public opinion on the cultural importance of the gradual shift from manuscripts to printed books appears to have been divided (see Love 1993, Marotti 1995, Beal 1998, Ezell 2003). Bacon, in 1620, aligns "printing, gunpowder, and the magnet" as three inventions that "have changed the whole face and state of things throughout the world" (New Organon, aphorism 129; in Bacon 1965, 373). In his later work, Hobbes prefers to downplay the impact of print when he calls the "Invention of Printing, though ingenious, [. . . ] no great matter" compared to the invention of letters as such (1996, 1.4; cf. Hobbes 1990, 109, 115-17). Others show greater concern and argue passionately against the effects of print culture, in texts which they nevertheless publish in print. In the late 1630s and early 1640s, Sir Thomas Browne sees quite clearly that the printing press has become an important weapon in English political and religious conflict, an invention that resembles the compass and the gun in its military use and its "incommodities" or destructive potential, which he deplores (Browne 2012, 30, Religio 1.24). Yet his political opponent John Milton understands the new predicament very well and engages in the production and distribution of republican propaganda by means of print. For those who justify their actions on the basis of Scripture, the availability of relatively cheap printed Bibles means more than a blessing for the individual benefit of the faithful - it is ammunition in the collective armed struggle of the godly against their less godly antagonists. In a letter of advice written for the future Charles II in 1659 by William Cavendish, the Earl of Newcastle, the point is made quite clearly that

18 Cf. Sharpe 2000a, 55: "The explosion of print during the 1640s created an audience more remote and anonymous, as well as numerous, than any before; an audience harder to read and define or to address from the pulpit of dedication. Moreover, the speed with which claims to truth were exposed by events or other publications undermined the rhetoric of dedications [. . .].” 
"controversey is a Civill warr with the Pen, which Pulls out the sorde soone afterwards." Cavendish sees increased literacy rates undermining governmental and ecclesiastical authority as well as social hierarchy: "The Bible In English under Every weavers, \& Chamber maids Armes hath Done us much hurte", he notes, adding nostalgically that "when Moste was Unletterd, it was much a better world, both for Peace \& warr” (Cavendish 1984, 21, 19, 20). Both sides in the Civil War, image-breakers as well as image-builders, appreciate and fear the transformative power of the printed word, for very good reasons (see also Scribner 1988, Watt 1991).

In a long-term perspective, the changes in early modern English literary culture can be read as a gradual and progressive disentanglement of different discourses. In this process, literary communication is increasingly understood as a medium of entertainment, associated with leisure rather than labour. But this new function of literature could be argued to emerge as a rather accidental side-effect because it is, and remains, to a large extent determined by external factors. The rules that specify how to read a text are not fixed by the texts themselves, however strongly such authorial control may be desired and asserted in prefaces and dedications. Literary history before 1700 is necessarily a history before 'literature' in the narrower modern sense because its object as we know it and have known it since Romanticism - literature as autonomous aesthetic communication - does not yet exist. This is not to say that readers did not appreciate aesthetic effects, or that imaginative writing was not supposed to give 'pleasure' - a key term in Renaissance as in classical literary theory - but this did not demarcate a particular kind of writing from other kinds of texts. In a wider European context, the proto-systemic differentiation of discourses belongs to the prehistory of Enlightenment attitudes towards public communication. It marks the basic intellectual trajectory traced in this study from humanism to neoclassicism and empiricism. The rationalism of the dawning 'age of reason' is based on a communicative ideal that is incompatible with the humanist literary strategies of persuasive rhetoric: to be acceptable, a proposition is not allowed to admit that it uses rhetorical strategies of adornment in order to convince others of its truth value.

Henceforth, literary techniques had to be banished from the court of philosophy like Hobbes from the court of Charles II: they would be protected and pensioned, but officially disregarded and kept within the bounds of a critical cordon sanitaire. ${ }^{19}$ In Dryden's satires of the 1680s, the priorities of literary decorum and socio-political observation have noticeably shifted in comparison with his earlier Restoration panegyrics, shifted towards a substantial weakening of the communicative bond between political and literary discourse that had formerly (e.g. in Davenant and Milton) been mutually inclusive. Other writers (e.g. Behn, Congreve, and Defoe) are keen to exploit

19 This thesis of a separation of discourses does not necessarily conflict with the observation that discursive norms can be relativised and parodied as soon as they have been established (e.g. in Cavendish, Shaftesbury or Swift); rather, the fact that they can be parodied and playfully treated asserts and confirms the general validity of a fairly stable system of discursive norms. 
this very weakness of connection, exploring the gaps that were opened up by this separation of discourses and developing new literary strategies from different 'angles of contingency' - literary strategies that, as I argue in chapter 5, coalesce into a prehistory of the eighteenth-century novel. This is not an accidental culmination of a protoliterary history from Burton to Behn, even though it is not the only possible one; but since the novel is one of the most fascinating cultural objects to emerge from the discursive turmoil of the seventeenth century, it is a special challenge to trace the intellectual and cultural foundations on which its literary epistemology is based. 